\title{
LAS HIJAS DE ANA FRANK. DIARIOS ÍNTIMOS Y ADOLESCENCIA
}

\section{Manuel Alberca}

\begin{abstract}
RESUMEN
En este trabajo, analizo tres diarios íntimos adolescentes, que forman parte de un conjunto de diarios inéditos, recopilados por mí entre los años 2000 y 2006, a raíz de una investigación sobre la escritura diarística, que recogí en La escritura invisible. Testimonios sobre el diario íntimo (Sendoa 2000). Estos diarios fueron escritos por muchachas españolas en las décadas setenta y noventa del siglo pasado. Aunque no podamos generalizar como conclusiones sus características ni menos aún extenderlas a las de un universo tan amplio y desconocido como el diario de las adolescentes, de su lectura y estudio extraemos algunos aspectos relevantes sobre cómo aprenden a llevar diario, sobre qué los contenidos registran y sobre cuáles son las funciones que cumplen en sus vidas la escritura cotidiana del diario.

Palabras clave: Diarios inéditos, adolescencia, España, 1970-1990, aprendizaje, contenidos y
\end{abstract} funciones.

\begin{abstract}
In this paper I analyse three diaries which belong to my book of personal diaries, La escritura invisible. Testimonios sobre el diario íntimo (Sendoa 2000), which I collected from 2000 to 2006. These diaries were written by Spanish girls from 1970s to 1990s. Although it would not be exact to generalize, nor jump into into general conclusions since we are dealing with a very wide subject, such as the diaries of adolescents, or their reading or study, we present here some relevant aspects connected with how teenagers keep a diary, what do they write about, and what importance writing a diary has for them in every day life.

Key words: Unpublished diaries, adolescence, Spain, 1970-1990, process of learning, contents and aims.
\end{abstract}

La adolescencia y la juventud son los únicos periodos que merece la pena vivir. Después, uno se repite.

Charles Juliet. Journal

La adolescencia es el momento en que más se encuentra la vida y sin embargo en el que más se va contra la vida.

Ramón Gómez de la Serna. Automoribundia

Dr. Manuel Alberca. Catedrático de Literatura Española. Universidad de Málaga. Correo electrónico: alberca@uma.es

Recepción: 30- 04- 2011

Aceptación: 19- 05- 2011 
Hace unos años me dediqué a sondear los fondos de la Biblioteca Nacional de Madrid. Buscaba en sus archivos diarios de adolescentes, pero debo confesar que no los encontré. Lo que descubrí nada tenía que ver con este tipo de diarios. Entre los escasos diarios publicados predominaban los de muchachas, cuyas vidas se consideraban edificantes de acuerdo con la moral política y religiosa de nuestra larga posguerra. Como botón de muestra, citaré dos: Así era María del Carmen. Su diario espiritual, de María del Carmen López Manchado, y el Diario de Juani, que firman Mariano Civera y José Ramos. Ambos diarios responden a un mismo esquema e intención. Se trata de dos vidas ejemplares de jóvenes modélicas, que en ambos casos murieron de manera prematura y dramática. La primera, a los 21 años a consecuencia de una grave enfermedad y la segunda, a los 19, al ser arrollada por un tranvía en la Ciudad Universitaria de Madrid. María del Carmen combina a la perfección el paradigma femenino de la época: es una convencida propagandista de la Acción Católica y una patriota, que tiene como modelo a la reina Isabel la Católica. Ya en el lecho de muerte, considera que ser soldado de Cristo dentro de la Acción Católica es el honor máximo para una joven. Por su parte, el diario de Juana Ayuso es "un testimonio de auténtico cristianismo" en palabras de sus editores, que han seleccionado y comentado el diario, suprimido y resumido según criterios que no explican. Hasta aquí las "hijas de María".

Se comprenderá que, con semejantes ejemplos impresos, me refiera por fuerza a los contados diarios inéditos de muchachas que he podido conocer y recopilar con mis escasos medios personales entre los años 2000 y 2006. En su variedad, estos diarios tienen en común haber sido escritos por muchachas adolescentes españolas entre las décadas setenta y noventa del siglo pasado. Personalmente, encuentro estos cuadernos más interesantes y mucho más representativos de este tipo de diarios que los citados. La mayoría de estos diarios (una docena) me fueron cedidos por las diaristas que colaboraron conmigo en una investigación sobre la práctica del diario en España, que daría lugar después al libro La escritura invisible. Testimonios sobre el diario íntimo (Alberca 2000). Ellas me hicieron llegar sus diarios adolescentes, cuando ya habían sobrepasado esa edad hacía casi un par de décadas. Fue sin duda un gesto de generosidad por su parte que yo correspondí cumpliendo en cada caso las condiciones de uso dispuestas por las autoras. Todas me prestaron sus cuadernos con la condición de que los leyese y se los devolviese. Algunas me permitieron fotocopiarlos. Otras me autorizaron sólo la lectura. Todos los devolví a sus propietarias una vez leídos. Me consta que la mayoría tenían la intención de conservarlos, pero en algún caso me confesaron que una vez los recibieran de vuelta los destruirían... Así que los diarios originales volvieron a su origen y allí deben estar en estos momentos, salvo en los que hayan sido destruidos. En mi poder, quedaron las fotocopias de algunos.

Me ocuparé sobre todo de tres que conservo fotocopiados, a los que denomino con el nombre de sus autoras: Diario de Antonia, Diario de Ester, de Ester Astudillo, y Diario de Rosa, de Rosa García, pero tendré en cuenta también el resto de diarios igualmente inéditos. El Diario de Antonia (pseudónimo) consta de tres cuadernos. Comenzó a llevarlo cuando tenía 12 años en junio de 1978 y lo cerró en enero de 1982. El primer cuaderno (18,5x14) es el clásico producto manufacturado y comercializado como regalo para adolescentes. Tiene pastas duras de color verde, que imitan piel, y con canto dorado en las hojas. En el mismo color dorado, escrito sobre la portada, se puede leer "Mi diario". Al comienzo le faltan un número indeterminado de hojas que presumiblemente ha arrancado la autora, según se deduce de la primera entrada, en un acto de autocensura literaria o moral. Consta de 76 páginas, todas escritas. El cuaderno 
es regalo de su abuela, según la misma diarista anota en la hoja de cortesía, y tal vez en este hecho anecdótico se encuentre la motivación o el desencadenante primero de su escritura. En esa misma hoja, la diarista pega su foto a manera de autorretrato físico. Cuando este cuaderno se completa (12 de abril de 1979), improvisa un soporte diarístico en un bloc de facturas que le da su padre. En éste, comienza el 26 de septiembre de 1979 y termina el 9 de mayo de 1981. Es posible que entre ambos escribiese en folios u hojas sueltas que no se conservan. El bloc de facturas pertenece a la empresa en la que el padre había trabajado como cobrador. Las facturas de $12 x 18$, en su reverso sin imprimir, le sirven para registrar sus entradas de intimidad. Cuando las hojas de talonario se acaban, un cuaderno escolar de espiral tamaño cuartilla será el tercer soporte utilizado. Abarca de junio de 1981 a enero de 1982.

El Diario de Ester lo componen dos cuadernos del tipo "Mi diario", ambos del mismo tamaño (21x16), pero de encuadernación diferente. El primero, que tiene las pastas duras de color verde, con los cantos de las hojas dorados, como doradas son las inscripciones de la portada, y dorada la tópica cerradura de seguridad, abarca desde el 14.12.1979 al 5.11.1982. El segundo, de diseño más moderno pero igualmente "femenino" como el anterior y con el consabido cierre con llave, va del 6.11.1982 al 18.1.1985. El primero es de 200 páginas y, según consta en el interior, es regalo de sus padrinos; el segundo tiene 134 páginas escritas, con dedicatoria incluida, y es regalo de su madre. Al terminar el primer cuaderno, continúa el diario en once folios, escritos por ambas caras, que dobla y guarda al final del primer cuaderno. El segundo está incompleto, quedan en blanco 10 hojas. Entre el final de la escritura cotidiana y estas páginas en blanco hay 3 páginas de anotaciones sin fecha, escritas en catalán con una letra ya adulta, que son el colofón de la historia sentimental, que había ocupado las últimas entradas, y cuyo final parece que determina la "muerte" del diario.

El Diario de Rosa lo componen tres blocs o cuadernos escolares de tamaño folio. En total suman 300 páginas aproximadamente. Cuando termina el cuaderno o cuando en un viaje no dispone de él, escribe en folios sueltos que después une al cuaderno. Incorpora algunas fotos de amigos, familiares o compañeros de clase, también algún dibujo o pequeño objeto que pega al cuaderno. Abre el diario el 10 de septiembre de 1987 y lo cierra 27 de enero de 1991. Como el de Ester, es un diario de notable continuidad y disciplina. El carácter tímido de la diarista y su acercamiento lento a los muchachos hacen que el cuaderno se transforme en un refugio protector de su intimidad. La correspondencia del diario como espacio de libertad se redondea cuando la adolescente consigue que sus padres la autoricen a utilizar una vivienda vacía de la familia como estudio personal. Allí el diario crecerá a sus anchas.

Aunque los tres diarios son bastante opacos con respecto a cuestiones sociales y políticas, como lo son la inmensa mayoría de los que conozco directamente o por referencias testimoniales, sabemos por el testimonio personal de las diaristas que la familia de la primera pertenece a la clase obrera urbana, y las otras dos a la clase media. Funcionarios la segunda y comerciantes la tercera. Por lo reducido del corpus estudiado, todo lo que pueda afirmar aquí debe ser entendido como una hipótesis y está necesariamente restringido a estos cuadernos y no pretendo generalizarlo a los que desconozco. Tampoco aspiro a elevar a categoría sociológica ni histórica ni de género sus contenidos, pero sin ninguna duda éstos nos enseñan cómo llevaban su diario algunas adolescentes de la transición democrática, cómo "aprendieron" a escribirlo, qué contenidos los caracterizan o qué función cumplían en sus vidas. No podrán ser conclusiones generales, si en un terreno tan lábil como éste eso es posible, pero sin duda la lectura de sus diarios nos acerca a esa edad tan difícil como desconocida y al conocimiento de sus problemas o preocupaciones a través de unos textos que no alcanzan nunca el honor de la imprenta. 
Como se puede deducir, si se atendiera sólo a los diarios publicados, podríamos hacernos una idea muy errónea de los diarios adolescentes, podríamos pensar incluso que este tipo de diarios no ha existido en España. Con esto quiero subrayar que para conocer qué son de verdad los diarios de adolescencia debemos abandonar lo que está publicado y adentrarnos en la inmensa masa de diarios desconocidos pertenecientes a jóvenes igualmente desconocidas. Dicho en pocas palabras, me coloco por convicción y por necesidad en la vía abierta por Philippe Lejeune para estudiar la práctica diarística (Lejeune 1989, 1990 y 2003). Entre las numerosas aportaciones que Lejeune ha realizado al conocimiento de los diarios, cabe destacar el haber desplazado el estudio del diario publicado, como se había hecho tradicionalmente, a la investigación de la práctica y las circunstancias de los diarios inéditos. Con este cambio de perspectiva, Lejeune ha ido revelando en sus sucesivos trabajos un territorio ignoto. Hasta entonces, los estudios literarios sólo tenían en cuenta un pequeñísimo porcentaje de los diarios, los que llegaron a la imprenta, y se desentendían de la mayoría, es decir, de aquellos que no suelen alcanzar los honores de la imprenta. Por tanto, edición y escritura diarística no se corresponden en absoluto, son dos mundos distintos. Lo ideal sería que, en la medida de lo posible, se pudiesen aproximar para conservar alguna representación de los diarios de la gente común.

Desde que tenemos datos precisos sobre la práctica diarística contemporánea sabemos que el inicio de la escritura del diario está ligado casi siempre a la edad adolescente (Lejeune 1990 y Alberca 1996; 1997). La mayoría de los diaristas comenzaron a llevar diario entre los doce y los dieciséis años. En España, el diario ha padecido un desprestigio inmemorial y los diaristas han sido tachados de narcisistas o de inmaduros. Esta descalificación ha influido negativamente no sólo en la práctica y en el aprecio de este tipo de escritura, sino también en el escaso interés por la conservación de estos diarios y en consecuencia en la falta de estudios. En esto como en tantos aspectos que conciernen a la escritura autobiográfica en España, se percibe la herencia negativa de la moral católica y de la intolerancia social, que han fustigado tradicionalmente al yo y su libre manifestación.

Por estas razones, a pesar de que el diario llevado en la adolescencia es el diario por antonomasia, el más numeroso y uno de los de mayor relevancia social y antropológica, apenas se le ha prestado atención. En el menosprecio de estos diarios, además de la falta de curiosidad intelectual y del rechazo moralista antes referido, ha pesado también el prejuicio de los estudios literarios que limitan o discriminan lo literario con criterios aristotélicos muy restrictivos. Esta cuestión merecería en otro momento una atención más pormenorizada, pero ahora no le daré más vueltas, y aceptaré de buena gana que hablar de los diarios de adolescencia supone asumir que uno se coloca voluntariamente fuera de lo que se entiende por literatura con mayúsculas. La exclusión de tan selecto club la encuentro coherente, pues, entre otras razones, en los diarios adolescentes, late una idea de literatura radicalmente distinta, que pone la escritura al servicio de la vida y no al revés.

He dividido mi exposición en tres apartados en un deseo de abordar las cuestiones que considero centrales para conocer el diario de las adolescentes: el aprendizaje, el contenido y la función de los diarios. Dicho de manera interrogativa: ¿Cómo aprenden a llevar diario? ¿Qué anotan o cuentan en sus diarios? ¿Qué función cumple la escritura del diario?

\section{El aprendizaje del diario}

La primera consideración que cabe hacerse es si el diario es una práctica natural o aprendida. A juzgar por la aparente facilidad con la que surgen los diarios adolescentes y 
la abundancia de estos, se podría pensar que es algo consustancial a la edad, pero no hay tal. El hecho de escribir un diario es antes que nada un hábito cultural, estimulado por un determinado cuadro socio-cultural. Existe una cierta predisposición psicológica a que en esa edad los jóvenes, las chicas sobre todo, anoten sus inquietudes y experiencias, pero ni es natural ni espontáneo, porque se convendrá conmigo que el hecho de escribir, de manera solitaria y secreta, lo que se acaba de vivir, puede ser cualquier cosa menos natural.

Entonces, ¿cómo aprenden a llevar diario las adolescentes? Las dificultades de este aprendizaje y la falta de modelos las destacan las propias diaristas que reconocen que no saben cómo se "hace" o cómo se debe llevar un diario. Comienzan su diario de manera intuitiva y con escasas referencias de lo que es un diario, pues, entre otras razones, la mayoría nunca ha leído uno. Pero empiezan, se lanzan a la escritura como los nadadores neófitos se tiran a la piscina, con más valor que arte. El Diario de Antonia es muy ilustrativo de esto, porque en el comienzo de su primer cuaderno se nota que ha arrancado varias hojas, lo que supone una corrección tanto literaria como moral:

\footnotetext{
He intentado muchas veces empezar este diario pero siempre sin éxito porque no me gustaba lo que escribía, o porque me parecían tonterías y lo he roto, pero esta vez es distinto, porque siento una fuerza dentro de mí que me impulsa a escribir mis ideas, las cosas que me ocurren y lo que pienso sobre todo lo que me rodea. (Diario de Antonia, 28 de junio de 1978)
}

Pero, casi un año y medio después, las mismas dudas subsisten. Tras haber escrito el primer cuaderno, Antonia se apresta a comenzar el segundo y en la primera entrada de su cuaderno nuevo insiste otra vez que no sabe cómo se escribe un diario:

\footnotetext{
La verdad es que a pesar de haber escrito uno no sé cómo se hace. En el otro sólo ponía tonterías, aunque tengo el presentimiento de que en éste las seguiré poniendo. No sé si debería hacer un pequeño resumen de todo lo que me ha pasado desde entonces hasta estas fechas. (Diario de Antonia, 26 de septiembre de 1979)
}

Pero a pesar de la inseguridad y de la falta de referencias o modelos diarísticos, el Diario de Antonia, y el resto de diarios citados al comienzo, son ejemplos de cómo en la España de los años setenta, a pesar de la falta de tradición editorial y de la escasa lectura de diarios, la práctica de escribirlos perduró. ¿Cómo se ha trasmitido el hábito de llevar diario? ¿Cómo aprendieron? ¿Por qué o por quiénes fueron estimulados?

En este sentido, cabe señalar tres estímulos: los escasos diarios editados, la influencia familiar de la que es corolario o prueba el regalo del cuaderno y, por último, el círculo de amistades, que, como es sabido, es tan influyente o más que la familia en esta edad. Hay un cuarto ámbito de influencia que es la escuela, pero en los cuadernos o testimonios que yo conozco su influencia es inexistente.

\section{1. Los diarios publicados}

El título del artículo alude al influjo del Diario de Ana Frank en el desarrollo del diarismo de las adolescentes españolas del último tercio del siglo XX, especialmente a partir de finales de la década de los setenta y sobre todo en los ochenta en que las ediciones de bolsillo permitieron una popularización del libro entre las lectoras más jóvenes. Las hijas que Ana Frank nunca pudo tener habrían coincidido en edad con las muchachas que escribieron los diarios que aquí estudio, en los cuales, a veces de manera explícita, está impresa la huella de Ana Frank. Es como si el ejemplo de la alemana hubiese fructificado en las diaristas adolescentes, cumpliendo por caminos imprevistos la función educadora y maternal que ella 
soñaba ejercer: "Pienso -apostilla Ana en su Diario después de una de las regañinas de su madre- que cuando tenga hijos querría ser para ellos la mamá que me imagino".

Por tanto, a falta de modelos literarios españoles, el ejemplo más sobresaliente para las adolescentes españolas del último cuarto de siglo, como para las muchachas europeas unas décadas antes, lo constituyó el Diario de Ana Frank. Por lo general, estas diaristas quieren imitarlo, su lectura les ha impresionado por múltiples razones y se convierte en un modelo a emular y en un estímulo permanente del suyo. Su madurez de juicio y su inteligencia quisieran tenerla para ellas, pero su figura de víctima del holocausto judío, su coraje y valentía les hace sentir insignificantes a su lado. Rosa comienza su diario con catorce años, cuando acaba de leer el de Ana Frank. Con anterioridad, tal como anota en el comienzo del suyo, ha habido otros intentos que fracasaron porque alguien los leyó, aunque reconoce que sólo anotaba cosas estúpidas como los deberes o lo que había comido. Ahora no. Ahora está más segura y convencida de lo que quiere escribir. Coge un bloc de matemáticas sin acabar del curso anterior, y para camuflar el diario lo etiqueta en la portada como si fuese de Religión, y comienza a escribir su primer diario, merecedor a su juicio de tal nombre, viva aún la impresión que le ha producido la lectura de Ana Frank. En la primera entrada de su diario, después de los consabidos protocolos de privacidad y "castigo eterno a los indiscretos" que osen leer sus secretos, hace un emocionado panegírico de su admirada Ana:

\footnotetext{
La lectura del libro de Ana Frank me ha proporcionado la verdadera imagen del diario, que es como si fuera el confesor de tu corazón. Voy a tomarlo como modelo para la elaboración de éste mi diario. Desde luego no se parecerá en nada, puesto que la vida de Ana Frank es totalmente distinta a la mía. Ella vive en una época más atrás, gobernada por fanáticos del poder, por locos (me refiero a Hitler y compañía) [...]. Jamás se podrá comparar su juventud perseguida con la mía casi en total libertad... (Diario de Rosa, 10 de septiembre de 1987)
}

Hasta donde yo puedo saber, esta influencia es tardía en España y lógicamente va ligada a la manera en que se difundió el libro entre nosotros. La primera traducción al castellano del Diario de Ana Frank se publicó en Argentina en 1952, con un emocionado y acertado prólogo de Daniel Rops. Esta sería, por tanto, la primera edición en lengua española del diario que tuvo escasa difusión en la España de aquel tiempo. La primera traducción hecha en España, con el título de Las habitaciones de atrás, es de 1955, aunque el depósito legal consta de 1958.

Por los registros de la Biblioteca Nacional de Madrid y de las sucesivas ediciones y reediciones del diario, se puede deducir que hasta finales de los sesenta y sobre todo a partir de la mitad de los setenta en que aumentan considerablemente las reediciones del libro, el diario de Ana Frank no circuló con la normalidad y en la cantidad que se difundió en la Europa democrática. Pero se puede asegurar que, en el tardofranquismo y en los albores de la democracia, el ambiente socio-político de aquellos años y, sobre todo, la publicación del Diario en edición de bolsillo hicieron que ocupase un lugar preferente entre las lecturas adolescentes, desplazando a los falsos diarios del abad francés Michel Quoist, que habían tenido una inmensa fortuna entre los jóvenes lectores españoles de los años sesenta, constituyéndose en una lectura catequística, formativa, ejemplar y casi obligatoria. Dicho con otras palabras, el modelo de diario adolescente laico o no confesional que representa el diario de Ana Frank vino a sustituir el modelo ideal y católico de los diarios ficticios de M. Quoist: Dar, Diario de Ana María y Amar, Diario de Daniel.

\subsection{La influencia familiar}

Pero, además de la lectura de diarios, reales o ficticios, su aprendizaje y práctica se han producido por lo general gracias a la motivación de la familia o de alguna persona del 
entorno familiar. A veces bastó ver a una hermana mayor, una tía o el abuelo, concentrados en la escritura, para que ese gesto adquiriera automáticamente a la vista de la adolescente un prestigio cultural, espiritual o de mayoría de edad y quisiera imitarlo. En la mayoría de los casos, el regalo de un cuaderno fue el estímulo inmediato para el inicio de la escritura calendaria, como lo fue para Ana Frank que recibió un cuaderno con cerradura como regalo por su duodécimo cumpleaños. Esa misma fue la motivación inicial para que Antonia y Ester, que lo reciben de su abuela y de su madrina respectivamente, comenzasen a escribirlo. Pero si no hay otros estímulos culturales en el entorno de la familia, la práctica decae al poco tiempo. Si el incentivo del regalo no se inserta en un marco sociocultural propicio, suele agotarse en sí mismo. En cambio, cuando el ambiente cultural de la casa acompaña, el regalo se inscribe en una jerarquía cultural que valora este tipo de escritura, consiguiendo la necesaria continuidad.

En cualquier caso, la escritura del diario, sobre todo en la segunda mitad del siglo XX, dejó de ser un privilegio o una práctica cultural burguesa para extenderse a los estamentos populares de la sociedad como consecuencia de la extensión y obligatoriedad de la enseñanza. De igual forma, la motivación de la familia es tanto mayor cuanto más presente está la cultura escrita en el ambiente familiar. Por eso, aunque la práctica actual del diario se presenta como libre y espontánea, no podemos ignorar que, tras el estímulo a la escritura o el regalo de un cuaderno, late un deseo contradictorio de control decimonónico, aunque no se ejerza o sea muy remoto. Contradicción que a veces también alcanza a las diaristas, pues al mismo tiempo que defienden el carácter personal e incomunicable de su diario, negándole a la madre su lectura, echan en falta no poderle comunicar los secretos que se confían al cuaderno a un lector ideal.

En muchas ocasiones, el regalo del cuaderno, en forma de libro con cerradura o candado, les invita a la escritura. Ese soporte es ya por si solo una promesa de sugerentes secretos y de excitantes aventuras, que son en realidad un sueño de edad adulta, un deseo de ser mayor ya, cuando todavía es pequeña. Los diarios juveniles empiezan así sin más, pero igualmente muchos no despegan o languidecen. Muchos cuadernos se abandonan por falta de disciplina, pero también, porque además de no conocer el lenguaje diarístico, les falta vida interior propia.

A veces el estímulo se adelanta a la necesidad o a la edad necesaria, cuando el futuro diarista es todavía un niño y recibe un cuaderno en forma de regalo de primera comunión o de cumpleaños. Los diarios infantiles, salvo que se inscriban en alguna tarea o deber escolar rara vez arraigan. En el cuaderno de Ester, se observa con claridad cómo se produce la transición del diario infantil al adolescente, aunque en este caso, también se produce, además de una maduración psicológica, el descubrimiento de la forma de poder dialogar o hablar consigo misma, aprendida en el Diario de Ana Frank, a la que me referiré al final de este trabajo (Alberca 2000: 281-289 y 293-306).

El regalo del cuaderno, ofrecido a las jovencitas casi en exclusiva, cuando proviene de la familia o de personas vinculadas a la familia, como padrinos o amigos de los padres, encierra un doble y tácito mensaje. Por una parte, es una incitación a la escritura, que el ambiente cultural de la familia mantiene o agosta, y también a la construcción de una identidad propia; por otra parte, instituye la posibilidad del control familiar. Como dice Lejeune, refiriéndose a los diarios de las "señoritas" del siglo XIX: "Porque lo que caracteriza a la pedagogía católica, es encomiar el diario tanto como se pueda controlarlo, y combatir lo que se escapa. El reclamo está en el centro del sistema de control" (Lejeune 1993: 423).

De hecho una parte de la vida de estos diarios gira en torno a la transmisión o no del diario a la madre, a su posible lectura indiscreta y al deseo contradictorio de comunicarlo o 
mantenerlo en secreto. La adolescente entiende que el diario es escritura de sí y para sí misma, en la que se encierra lo que quisiera que quedase en secreto y vedado a los demás, aunque la madre de hecho por consentimiento o por indiscreción lo puede leer a veces completa o parcialmente.

\section{3. Las amigas}

Si la familia cumple un papel de estímulo, no es menos cierto que esta influencia es mayor en la infancia y menor en la adolescencia. En la adolescencia, el círculo de amistades adquiere mayor protagonismo que los padres y en consecuencia, la escritura del diario, compartido con otras amigas, tiene mucho de gesto o hábito grupal, pues la adhesión a dicha práctica responde muchas veces a un deseo de mayor integración en el grupo. De los diarios que conozco el que da idea mejor de esta clase de vida de amistad y camaradería es el Diario de Matute (apodo con el que la autora gusta ser llamada por sus amigos). Este diario, que conozco sólo parcialmente, está escrito entre el final de 1969 y 1971 en un internado mixto de un pueblo cordobés, de aulas y dependencias separadas, pero en el que se podían compartir recreos y salidas. Una muchacha de catorce años anota en su diario, durante casi dos cursos, la reiterativa pero intensa vida del internado. Durante los primeros meses las anotaciones son individuales, pero a partir de un momento comienza a compartir el diario. De manera repentina, el cuaderno deja de ser confesional y privado, para convertirse en un instrumento comunicativo entre los chicos y chicas del grupo. El diario registra los primeros enamoramientos y, al autorizar la lectura a los chicos por los que se interesa, les muestra aspectos desconocidos de su personalidad. El muchacho lee el diario y se lo devuelve con el consiguiente comentario personal, en el que razona sobre las dudas y vacilaciones que la relación le crea. Una vez que Matute descubre el poder comunicativo del diario repetirá la operación con otros chicos y amigas, que a su vez lo devuelven con los comentarios que le sugieren las anotaciones de la diarista. A partir de un momento, el cuaderno se deposita en un escondite al que tienen acceso los miembros del grupo que van dejando allí testimonio de sus atribuladas relaciones. El diario, por tanto, se abre al grupo y se convierte en la crónica cotidiana de la pandilla con sus amistades y odios "a muerte". En este orden, destacan las incidencias y alternativas de las relaciones de la autora con sus enamorados, hasta quedar monopolizada la escritura por estas vicisitudes.

En la adolescencia, el diario tiene mucho de contagio, pues es una edad que afecta a la camaradería o la conquista de la confianza y la confidencialidad de las amigas, que en esta edad está relacionada con el distanciamiento o desconfianza de los padres. Es la etapa en que los jóvenes se inventan su propia familia, estableciendo una fraternidad entre colegas, que suplanta aquella otra que normalmente se considera impuesta o irrelevante. Pero al mismo tiempo y quizá porque en esta edad son muy frágiles e inestables las alianzas amistosas, el cuaderno se convierte en la última instancia de la amistad, el amigo o la amiga por antonomasia, por lo menos hasta que la diarista encuentre una relación sentimental estable. Entonces, en un porcentaje alto, el diario es abandonado.

\subsection{La escuela y la institucionalización de la enseñanza del diario}

En el siglo XIX, la práctica del diario estaba institucionalizada. Fueron la familia y la escuela las que reconocieron y otorgaron a éste su carácter instructor y formativo. Precisamente por esto, el diario estaba abierto al tutelaje familiar o escolar o al menos era susceptible de ser leído por la madre o la preceptora (Perrot y Corbain 1989). En los diarios estudiados, no parece 
que en el mantenimiento de la práctica del diario pese mucho la escuela, pues en muy pocos casos de las respuestas a los cuestionarios y de los testimonios recibidos se cita esta como motivo o estímulo del mismo (Alberca 1997 y 2000).

¿Es preciso enseñar a escribir un diario? Nos puede resultar extraña esta pregunta teñida de un exceso de paternalismo, pero hay que señalar que muchos jóvenes comienzan reconociendo que no saben cómo escribir su diario, ni cómo empezarlo ni llevarlo, pues entre otras razones no han visto nunca uno.

Existen manuales de la enseñanza del diario, que cumplen una función de invitación y estímulo a escribirlo, como J'écris mon journal intime (Amblard y De Givenchy 1997), publicado por una editorial francesa para jóvenes, que está ilustrado con fragmentos de diarios reales depositados en la asociación juvenil católica de Orleáns, Vivre et l'écrire. En España, no hay nada equivalente, pues El diario personal. Propuestas para su escritura (Gúrpide, Falcó y Bernard 2000), que es, a mi juicio, una propuesta confusa, está concebido como una serie de ejercicios escolares de escritura en forma de diario con ejemplos o modelos literarios en los que la mayoría no son diarios, si acaso relatos de ficción en forma de diario.

\section{Las ganas de escribir}

El regalo del cuaderno, el estímulo de las amigas, incluso la lectura de Ana Frank, no son suficientes si faltan las ganas de escribir. Sin la urgencia de desbloquear el corazón o de aclarar el propio pensamiento no arrancaría ningún diario adolescente. Sin "desgracias", sin pesadillas y sin sueños imposibles no se pondría en marcha el motor de la escritura. El aprendizaje del diario va unido al aprendizaje de la vida, al conocimiento de los propios límites, del lado oscuro o negativo de uno mismo. En el diario, la adolescente va depositando o escondiendo todo aquello que considera más privado y frágil de sí misma.

La adolescencia es considerada habitualmente como la edad de las contradicciones y de las pulsiones encontradas. De acuerdo con esto, las adolescentes son al mismo tiempo juguetonas y dramáticas, impulsivas y tímidas. Se debaten entre la exaltación vital y la atracción del abismo. No parece una pequeña contradicción tampoco el hecho de escribir un diario, justo cuando la vida reclama con nuevas experiencias en esta edad crucial. Pero no hay contrasentido, el adolescente vive más intensamente los cambios y particularidades de su metamorfosis vital con la mirada puesta en la escritura del diario.

Los diarios de las adolescentes son la crónica de una profunda metamorfosis y por tanto responden a lo que conocemos como diario de crisis, es decir, cuando la escritura acompaña los cambios que amenazan o rompen la que hasta entonces constituía la cotidianeidad de la diarista, y termina cuando esos cambios se integran en la normalidad. El diario es tanto más intenso y significativo en la medida en que el mundo de la diarista, hasta hace poco infantil, comienza a ser asaeteado por las dudas y desconciertos producidos por las novedades que atraviesan la vida y la personalidad de la adolescente, pues la biología y la psicología les sorprenden, cuando el cuerpo y la mente les cambian de buenas a primeras. Un fragmento del Diario de Ester nos da una idea exacta de las transformaciones externas e internas que percibe la muchacha y la ansiedad con que las vive:

¿Sabes? -le pregunta Ester a Olga, su interlocutora ficticia-, estoy sufriendo un cambio, pero no como los que te hablé ya. Ahora es mi carácter el que se transforma. Mis deseos, mis inquietudes han cambiado además de la vida. Cada día me veo más lejos de mis padres. Ahora que es cuando más los necesito, mi corazón lucha por ser como antes, pero mi cuerpo, ¡ay mi cuerpo!, va como loco, les contesta, les reprocha y a veces ni les hace caso. (Martes, 2. II. 82) 
El supuesto paraíso de la infancia, el mundo dorado del niño comienza a tambalearse y emergen otros mundos desconocidos, quizá apetecidos, pero al mismo tiempo preocupantes. La adolescencia es en sí misma una edad crítica, llena de nuevas expectativas, pero también de mayores temores. Es un momento crucial, en el que la joven sabe que ya no es ni puede ser niña, pero tampoco se le reconoce como adulta. Le gustaría serlo, pero le atemorizan los cambios que presiente. En el comienzo de su Diario, Antonia reconoce con una claridad apabullante la etapa crítica en que acaba de ingresar:

Hasta ahora no me ha gustado la vida que he llevado, he precipitado demasiado las cosas y esto sólo me ha
llevado a darme cuenta de lo absurdo que es el querer ser mayor antes de tiempo. Sólo tengo 12 años y ya
sé lo que es una sala de fiestas, [...] y la verdad no me alegro sino que me entristezco por ello y por eso he
decidido cambiar desde hoy. He decidido empezar de nuevo y la verdad es que me siento mucho mejor, he
recuperado mi alegría y mi niñez que, a pesar de mi corta edad, se me estaba escapando. (Diario de Antonia)

Sin embargo, al día siguiente, y en un arranque de madurez y de realismo sorprendentes, recapacita sobre su irreal proyecto de cambiar de vida y añade:

\footnotetext{
Esto de querer empezar una nueva vida no es nada fácil, o mejor dicho, es IMPOSIBLE, porque el tiempo no puede volver atrás. Y unos días después apostilla: Estoy pensando en la tontería que escribí el primer día que empecé el diario. Hace justamente una semana. ¿Cambiar de vida? ¡Qué "chalaura” como si fuera tan fácil! (Diario de Antonia, 5 de julio de 1978)
}

Pero la vacilación perdura. De hecho, la duda y el conflicto, entre la idea de lo que debería ser y de lo que en realidad es, abarca todo el diario de comienzo a fin, hasta hacer simétricas la primera y la última entrada del cuaderno. El diario registra sobre todo la lucha consigo misma. Siente que ya no es una "niña pequeña" y al mismo tiempo desea retroceder al pasado. Esta contradicción da aliento a la escritura y mantiene vivo el diario, a pesar de la pereza confesada de la diarista y de lo ajena que resulta la escritura a su medio social.

Los diarios de estas adolescentes son por lo general monotemáticos. Se centran obsesivamente en algún tema: la sexualidad, el amor y los chicos, la fidelidad o la traición de las amigas y, en menor medida, la relación con los padres. Temas todos ellos que viven con pasión y dedicación exclusiva y en constante conflicto o exaltación y, en consecuencia, se desentienden de todo lo que no tiene que ver directamente con el tema en cuestión. Es como si para ellas desapareciera el resto del universo y habitasen solitariamente en una isla.

Los momentos más cruciales y conflictivos de estos diarios son aquellos en los que afloran los problemas específicamente sexuales, aunque estos emerjan de manera indirecta o camuflada la mayoría de las veces. En el Diario de Antonia, la sexualidad se revela de manera elíptica, nunca directamente, si acaso a través de algunas reminiscencias en forma de comentarios o arrepentimientos. Este diario arranca, sospecho, de una de esas crisis: presumiblemente la diarista ha tenido una experiencia sexual que la ha desconcertado, asustado o creado remordimientos y el diario viene a intentar recomponer un equilibrio o una armonía anteriores, a la que, como ya se ha dicho, no podrá volver. Al menos en otras dos ocasiones se repite una situación similar a la que ya hemos leído en el comienzo del diario:

\footnotetext{
Me echó el brazo al hombro, cosa que me extrañó. Bueno no quiero dar detalles de lo que pasó, pero diré lo más importante. (No quiero dar detalles porque lo que quiero es olvidarme de esa 'chalaura' tan tonta y si lo escribo, pues cuando lo lea pues me volveré a acordar). En fin se me declaró, mi propio primo, la verdad como no me fío nada de él no me lo creí [...]. Me dijo que era en serio y al final le creí, pero como tengo hecha una promesa a Dios de no salir con niños, ni nada por el estilo, pues se lo dije. (Diario de Antonia, 7 de octubre de 1978)
} 
Los diarios, que en apariencia parecen dar muchos detalles y ser prolijos hasta la saciedad, resultan en realidad muy opacos, pues se extienden sobre los sentimientos, reacciones, es decir, sobre las consecuencias, pero omiten con frecuencia sus causas. En los diarios de estas adolescentes, los conflictos sexuales muchas veces aparecen de manera indirecta e inexplicable para un lector desprevenido. En el Diario de Antonia, por ejemplo, leemos con todo detalle las reacciones angustiosas por unos hechos que no se explicitan. A veces el Diario de Ester, por lo general más informativo que el anterior, nos pone enfrente de su agudo malestar, pero sólo nos llega su desahogo impotente:

\footnotetext{
Hoy es uno de esos días en los que estoy tan enfurecida que, que..., bah!, de qué sirve decirlo. De nada. Además no te lo puedo decir con palabras. Es algo que sólo se puede sentir en aquellos momentos de achaque. No puedo hacer nada [...]. ¿Qué me pasa? Tengo ganas de chillar... (Diario de Ester, 26. VI. 81)
}

El conflicto con los padres nace muchas veces a raíz de las primeras relaciones amorosas. La adolescente se aleja de sus progenitores de manera afectiva, pero todavía no puede establecer relaciones estables y vive en contradicción. Por lo general, aspiran o sueñan una independencia económica que les es imposible, pues todavía están al margen de la vida productiva y su mundo sigue siendo todavía el escolar.

\section{La afirmación de la identidad}

¿Por qué es tan importante el diario para los adolescentes y por qué se entregan a su escritura de manera tan intensa y apasionada? Con otras palabras, ¿qué función cumple el diario en esta edad? Como ya he dicho y es de sobra conocido, el diario cumple para las adolescentes una importante función de liberación expresiva, de catarsis y desahogo y de explicación consigo misma. Como han señalado Philippe Lejeune (2004) y Danielle Corrado (2004) a propósito de los diarios literarios, el cuaderno y la escritura de este se convierten también en un cobijo autohospitalario en el que escribir lo que no se puede o no se quiere decir a nadie. Ester, al igual que Ana Frank, inserta juicios valorativos del significado de su diario:

\footnotetext{
Mi diario significa un gran consuelo para mí, pues sin él no sé lo que haría. Cuando me desespero, escribo lo que siento y, mira, la furia se me pasa y empiezo a ver más claramente la realidad. (Diario de Ester, domingo, 1. III. 1981)
}

Ahora quiero detenerme en otras dos funciones del diario adolescente. En primer lugar, me referiré al diario como un instrumento didáctico y tecnológico del dominio del tiempo. A través de la escritura del diario, la adolescente entra con total derecho en la concepción temporal que rige el mundo de los adultos. Durante la infancia, el niño concibe el tiempo como una dimensión ilimitada, circular e inmóvil, que no le afecta en su vida cotidiana. En cambio, en la adolescencia, comienza el aprendizaje del tiempo lineal, histórico y cronológico, único e irrepetible. El diario, con su lógica calendaria, con sus anotaciones fechadas y con su carácter notarial, permite al adolescente aprender las inexorables leyes del tiempo y sus rigurosos mecanismos. Aprender a dominar el tiempo implica adentrarse en las medidas del mundo adulto y percibirlo en su triple dimensión de presente, pasado y futuro. Dicho de otra manera, empiezan a comprender el inevitable desdoblamiento temporal al que continuamente se enfrenta el adulto, que vive el presente escindido entre lo que ya vivió en el pasado y lo que espera o teme vivir en el futuro.

Por eso, aunque los adolescentes nos sorprenden con sus prematuros comentarios rememorativos de su cercana infancia, no dejan de ser consecuentes con este deseo de 
abandonar el tiempo propio de la infancia para entrar en el de los adultos. Cuando los adolescentes carecen todavía de biografía y de la necesaria distancia temporal que conlleva recordar, imitan los gestos de la experiencia de los mayores en sus diarios. En su Diario, Ester habla del miedo a la "falta" de biografía: "Imagínate que nada extraordinario ocurriera en mi vida a lo largo de los años. ¿Qué sería de mí entonces? Como un desperdicio desaprovechado y tirado a la basura de cualquier modo y de quien nadie se acuerda" (Miércoles, 4.11.81). Del mismo modo, fantasea con una vida de notoriedad y fama como cantante de éxito. En este sentido, el mismo hecho de llevar un diario, secreto para los adultos, alimenta la fantasía o el deseo de independencia. Por ejemplo, Ester entona su particular canto nostálgico de la infancia, que en el fondo es una manera de representarse mayor y de aparentar una identidad adulta que ella misma sospecha que es aún imposible y lejana:

\footnotetext{
¡Somos ya tan viejos! -se lamenta Ester cuando no tiene todavía catorce años-. ¡Qué hermoso sería volver a ser niños y volverlo a vivir de nuevo, con todas las experiencias pasadas! El tiempo ha pasado y nuestra oportunidad con él. Adiós dulces y antiguos momentos y adiós a los presentes, que, tal vez dentro de algún tiempo, puedan convertirse también en dulces, ya que lo que apreciamos es el pasado y sus experiencias, y en cambio el presente lo desaprovechamos sin darnos cuenta de ello. (Diario de Ester, Miércoles, 14. X. 81)
}

En segundo lugar, el diario cumple una función capital en la afirmación del sujeto, pues ayuda al descubrimiento de la complejidad identitaria. El diario registra el proceso a través del cual un adolescente afianza o construye su emergente e incierta identidad, en relación conflictiva con los padres, con los amigos y consigo mismo. Además de tabla de salvación, el diario se convierte en el espejo en el cual se va a ir reconociendo y dibujando una personalidad nueva, original e incierta. Sus anotaciones son un observatorio privilegiado en las se puede seguir la paulatina definición de una identidad en formación.

El gran descubrimiento del adolescente es el de su propio mundo interior, el reconocimiento de su otro yo, con el que mantiene un tenso y continuo diálogo, con el fin de integrar y reconocer como propia la imagen íntima que contradice la imagen que hasta entonces consideraba única. Por ejemplo, Ana Frank habla de "las dos Ana": la extrovertida y la introvertida, la que conocen los demás y la que conoce solamente ella, la divertida y temeraria y la que quiere amar y ser tierna. Quizá en la infancia, el niño experimenta esto mismo, pero, bien por ser menos consciente o por carecer del dominio de la escritura, no lo puede expresar. En los diarios adolescentes, se comienza a entender la identidad como las caras opuestas de un prisma: la exterior y la interior, la verdad de los demás y la verdad propia y la realidad infantil frente a la realidad de la etapa recién inaugurada. Y, como le ocurre a Ana Frank, este descubrimiento produce sorpresa, fascinación y ensimismamiento.

En esta mirada al mundo íntimo, la adolescente idealiza el propio yo, considerándolo como una identidad espléndida y romántica, en la que se le revela una nueva realidad, insospechada y desconocida hasta ahora, que observa con un instrumento inadecuado como es la característica fantasía infantil. El narcisismo de esta etapa y la incapacidad para armonizar el yo soñado con el yo real se producen en un periodo de "excitación sexual difusa", que se puede considerar normal en la formación del sujeto, siempre que no se prolongue (Debesse 1964).

Ya he dicho que un adolescente es una persona que adolece o sufre la enfermedad de la edad en la que ya no es niño y todavía no ha llegado a ser mayor. El adolescente es por definición alguien que se siente imperfecto o en una estación de paso, algo que no es exclusivo ni de los adolescentes ni de sus diarios, pues también los adultos llevan diario con la incierta esperanza de que se produzca un cambio largamente deseado y terminan sin haber alcanzado 
la madurez ni ajustado las cuentas consigo mismo. Por eso, los diarios adolescentes, como las plegarias, invocan que se cumpla el deseo de cambiar íntimamente, de llegar a "ser otro", bien por el desplazamiento de la identidad infantil o por la adecuación de esta a la adolescente.

El Diario de Rosa muestra el afán de alcanzar una "personalidad joven" (le molesta sobremanera el calificativo adolescente), pero su fantasía infantil la traiciona una y otra vez. Rosa tiene 14 años cuando comienza su diario. Con anterioridad, hizo algún conato de llevar diario, pero fracasó. Ahora, después de leer a Ana Frank, como vimos antes, se siente más segura y decide retomarlo. El motivo profundo del diario reside en la búsqueda ansiosa de un enamorado y en consecuencia su confidente será un chico. Sus amigas y camaradas, primero del colegio y después del instituto, han comenzado a tener sus primeras parejas amorosas. Ella no quiere ser menos, quiere experimentar en sí misma lo que escucha o ve a su alrededor. Sin embargo, sus ganas no se corresponden con sus posibilidades. Aunque ella no lo reconozca o luche por contradecirlo, su psicología sigue siendo la de una niña. La diarista traslada la característica fantasía infantil a su obsesión por los chicos y al deseo de ser amada y de amar. Sin fundamento alguno y a partir de gestos mínimos, como saludos o miradas, su deseo de amor la engaña y la equivoca. La muchacha elucubra y hace un despliegue de imaginación portentosa, pues interpreta los signos insignificantes como mensajes de amor, en fin, levanta continuamente castillos de arena, que se le desmoronan en seguida. A cada intento de contacto, sigue una frustración amorosa y el consiguiente repliegue en sí misma, cuando no una huida hacia delante. Este ir y venir de la ilusión al desencanto amoroso ocupa el $90 \%$ del diario.

$\mathrm{Su}$ ansiedad se hace obsesiva y la situación le llega a afectar al rendimiento escolar, incluso sufre una anorexia nerviosa durante algún tiempo. El periplo hacia la madurez será largo. Durante años, le resulta imposible comprender sus errores, y los seguirá cometiendo, confundiendo sus deseos con la realidad. Su inmadurez amenaza con hacerse crónica, pero precisamente las opiniones contrastadas con las amigas, la relectura del diario y el desplome del imaginario mundo interior al chocar con el real le obligan a reconocer su prolongado autoengaño y anota:

\footnotetext{
[...] a veces me siento avergonzada de mí misma, cuando hablo de una cosa que sólo duró quince días, y yo me lo tomo tan en serio como si eso hubiera sido una hecatombe. [...] Odio ser tan romántica, tan irreal, tan soñadora y tan sensible [...], porque al final descubro que no dejo de ser una estúpida. [...] Antes me sentía orgullosa de mí misma. Hoy ya no... (Diario de Rosa, 7 de diciembre de 1989)
}

En este momento, se puede situar la decisión de acabar con su complaciente narcisismo e iniciar una etapa autocrítica, no sin vacilaciones y tentaciones regresivas. Un verano, cuando tiene 17 años y está próxima a entrar en la universidad, decide simbólicamente clausurar su infancia de una vez por todas. Aprovecha unas semanas fuera de la tutela familiar, para iniciar por fin el cambio tantas veces pospuesto. Conoce el amor real sin platonismos ni fantasías infantiles y la transformación es total, mágica. Como no tiene el diario, anota en unos folios la experiencia de aquellos días en una larga y única entrada que después agrega al cuaderno (27-7-1990). Parece que habla otra persona, tiene una voz distinta, más fuerte, segura, madura. Es el comienzo de su particular conversión. Unos días después comenta con orgullo su gesta de vacaciones y concluye:

\footnotetext{
Ha sido una locura. Una locura genial de la cual no me arrepiento. Me lo he pasado en grande. Lo necesitaba. Necesitaba salir de aquí. Necesitaba no leerte. Ya habrás visto mis cinco folios del día 27. Pues sí, así ha sido. [...] No me arrepiento. Con cada uno de los chicos he experimentado un tremendo placer, un goce genial que nunca había sentido. He aprendido una de las cosas que me faltaba por saber... Eso en el plano superficial. Pero en mi interior, ¿cómo ha repercutido? Muy positivamente. [...] Mis exagerados romanticismos han caído. (Diario de Rosa, 14 de agosto de 1989)
} 
Decide también cambiar de nombre. Ya no será más Rosa María, sino Rosa a secas, un cambio mínimo pero significativo, pues como ella comenta:

Por fin me pudo Rosa. Me di cuenta de que no es que tenga poca personalidad. Es que tengo dos bien y claramente definidas tan diferentes la una de la otra. Una es la que ya me es propia, la que quiero mantener. Otra es la que fue mía. (Diario de Rosa, 22 de octubre de 1990)

En la construcción de la identidad juvenil, a la que sin duda el diario ayuda, tiene una indudable importancia el hallazgo del cauce expresivo de la relación epistolar con un destinatario ficticio, sea el diario, la amiga o un amigo ideal. Este invento discursivo es un recurso rudimentario, pero se revela como una herramienta fundamental, pues permite a la diarista objetivarse y le facilita el diálogo consigo misma. Ana Frank, "inventora" de este procedimiento encuentra en el distanciamiento de la amiga ficticia un medio de autoconocimiento:

Es muy raro eso de que a veces yo misma me vea a través de los ojos de otra persona. Observo lo que le pasa a una tal Ana Frank con toda parsimonia y me pongo a hojear en el libro de mi vida como si fuese ajeno. (Diario, Anna Frank)

La carta al amigo ficticio o la apelación al cuaderno (el tradicional "querido diario") como un paciente y comprensivo interlocutor permiten al adolescente iniciar una suerte de diálogo introspectivo. En mi opinión, esta suerte de desdoblamiento, que propicia la carta al interlocutor ficticio, le ayuda a ir descubriendo el otro de sí mismo. Asomarse a estos diarios es asistir a la génesis del sujeto, en el momento en que se dice "yo" con pleno derecho. Aquí comienza el camino del necesario desdoblamiento y distanciamiento que le pone en la pista de la difícil madurez.

El mejor ejemplo para ilustrar esta mudanza la encuentro en el Diario de Ester. Ester comienza su diario a los 12 años y después de 9 meses, es como si no supiera arrancar, pues en ese tiempo ha escrito sólo unas páginas de su cuaderno. Todo parece indicar que el diario va a naufragar por falta de materia y aliento, pero justo en ese momento, la diarista se inventa un destinatario ficticio, su amiga Olga - clara deuda con la Kitty de Ana Frank, cuyo diario acaba de empezar a leer- y la escritura da un giro completo: se problematiza y se enriquece con matices personales y expresivos. Es una verdadera epifanía diarística. La escritura y el contenido ganan enteros y su lectura nos enseña un ejercicio introspectivo delicioso, de una insospechada profundidad, que personalmente me cautivó. El diario empieza a funcionar cuando la escritura comienza a ser transitiva, aunque para ello se sirva de un destinatario ficticio. En este caso, la imitación de un modelo prestigioso hace finalmente posible el desarrollo del diario. En la entrada del 22 de septiembre de 1980, que comienza con un estilo diarístico infantil, para trasmutarse de golpe, leemos:

Verás, hoy se me ha ocurrido una idea, y será que para que la lectura de este libro no resulte tan monótona,
me siento inclinada a contarle la vida a una amiga, y esa amiga serás tú. Bien Olga. Tú serás la que
compartirás mis alegrías y mis penas, junto a mi mejor amiga, Chus. Es muy buena chica y siempre nos
lo contamos todo. Todo menos una cosa que por ahora no le puedo decir. Bien, a ti te la diré, y es que
la regla me vino en diciembre, y yo le he dicho que en julio. Por lo demás, no tenemos ningún secreto,
vamos, digo yo. Se despide por hoy

Ester

La invención de la amiga ideal resulta clave para el hallazgo de la identidad personal. El paso del diario infantil al adolescente coincide con el descubrimiento del significado del secreto y la mentira que no es otra cosa que la mayor conciencia de la complejidad de sí misma 
y del mundo. Representa un descubrimiento capital, pues desde entonces el diario acogerá aquello que no se ha contado a nadie o que se prefiere guardar para sí.

Como en los antiguos cuadernos de navegación, el diario adolescente adopta la forma de una cartografía personal, en la que se registran las incidencias de la travesía de la vida, con sus puntos de peligro y sus señales salvadoras. En cada anotación, se marca la distancia entre lo que se desea o se espera alcanzar y lo que la realidad ofrece. Cada "desgracia" de la adolescente, cada regañina de los padres, las traiciones de las amigas o las peleas amorosas sirven para comprobar la inevitable distancia entre los sueños y la realidad. El diario ejemplifica esa doble vertiente de la identidad adolescente. En la superficie, las anotaciones van dando cuenta de los quebrantos que los hechos y el tiempo inflingen a la diarista, al tiempo que le advierten que ya no puede vivir en el mundo de la fantasía sin grave peligro de alienación. Pero, de manera subterránea, la diarista adolescente aspira a restaurar y dar forma a la que quisiera llegar a ser, la que siente ser o desea hacerse. El diario cumple en este sentido un papel primordial de ajuste íntimo. En ese ir y venir de la realidad de los hechos al deseo de los sueños de ser otro, el sujeto adolescente se va configurando. Cuando no sucede algo digno de ser anotado, el reiterado "hoy nada", "hoy como siempre", esa salmodia de los diarios adultos e infantiles, la afirmación del sujeto se estanca. En cambio, cuando se altera o se rompe la cotidianeidad, el sujeto se arma tomando como referencia la mismidad quebrada.

\section{Conclusiones}

Al leer los diarios de las adolescentes, quizá cualquier diario inédito, a veces también los editados, conviene tener presentes algunas de sus particularidades o dificultades de lectura para no llegar a conclusiones erróneas. Los diarios de estas adolescentes son discursos descontextualizados sobre el yo, que apenas nos proporcionan datos del origen y circunstancias de los diarios mismos. En mi caso, los testimonios epistolares de las diaristas me han ayudado a situarlos y a leerlos mejor, pero no por ello desaparecen algunas zonas oscuras.

Los diarios, que parecen dar muchos detalles y ser prolijos hasta la saciedad, resultan en realidad muy opacos y elípticos, pues se extienden sobre los sentimientos, reacciones, es decir, sobre las consecuencias, pero omiten con frecuencia las causas. En los diarios de estas adolescentes, los conflictos sexuales muchas veces aparecen de manera indirecta e inexplicable para un lector desprevenido. En el Diario de Antonia, por ejemplo, leemos con todo detalle las reacciones angustiosas por unos hechos que no se explicitan. Como arriba anoté, se extienden y nos informan sobre las consecuencias de unos hechos que desconocemos en su factualidad. A veces el Diario de Ester, por lo general más informativo que el anterior, nos pone enfrente de su agudo malestar, pero sólo nos llega su desahogo impotente: "Hoy es uno de esos días en los que estoy tan enfurecida que, que..., bah, de qué sirve decirlo. De nada. Además no te lo puedo decir con palabras. Es algo que sólo se puede sentir en aquellos momentos de achaque. No puedo hacer nada (...). ¿Qué me pasa? Tengo ganas de chillar...” (26. VI. 81).

Los diarios adolescentes son por lo general monotemáticos. Se centran obsesivamente en algún tema: el sexo y sus sustitutos, los chicos, la fidelidad o la traición de las amigas, la relación o la dificultad de relacionarse con los padres, etc. Es decir, se desentienden de todo lo que no tiene que ver directamente con el tema en cuestión. Es como si para ellas desapareciera el resto del universo, y habitasen solitariamente en una isla. Omiten sin premeditación todo lo que no tiene que aparecer, para focalizar e iluminar el centro de sus preocupaciones. 
En tanto que crónica menuda del vivir cotidiano, estos diarios incurren aparentemente en la banalidad o en la superficialidad, sobre todo en su modalidad más infantil, punto de partida de los de la adolescencia en ocasiones (Diario de Ester). Sin embargo, en muchas ocasiones, esta banalidad es sólo aparente, puesto que, tras una extenuante relación de hechos y datos, los adolescentes pueden cifrar o esconder sus verdaderos sentimientos o intereses sin dar otras pistas. Algo así como ocurre con esos elementos (servilletas, tickes, entradas, flores secas, entre otros) y pequeños recuerdos que se añaden al diario, sin ninguna palabra de comentario, pues para la diarista es innecesario: éstos le evocan directamente lo que no se nombra ni se quiere nombrar.

Al final, un sentimiento contradictorio me embarga, pues si bien estoy convencido del valor de estos diarios adolescentes como testimonios personales y sociales, irremplazables para conocer mañana la vida cotidiana y cómo forjaban su identidad las jóvenes españolas del final del siglo XX, también sé que de no mediar algún milagro no se librarán con toda probabilidad del olvido y de la pérdida, cuando no de su lamentable destrucción, si antes no conseguimos salvarlos.

\section{Bibliografía}

Alberca, Manuel. 1996. "La pratique du journal intime en Espagne. Enquête auprès de la population scolaire de Málaga”. La Faute à Rousseau. 13: 54-56.

1997. "La escritura del diario íntimo, hoy (Encuesta)". Boletín de la Unidad de Estudios Biográficos. 2: 11-25

2000. La escritura invisible. Testimonios sobre el diario íntimo. Prol. Philippe Lejeune. Oyarzun: Sendoa.

2010. "El diario o el momento de la verdad". Mercurio. Revista para el fomento del libro y de la lectura. 122: 14-15.

Amblard, Odile y Pierre de Givenchy. 1997. J'écris mon journal intime. París: Martinière / Jeunesse.

Anónimo. 1989-1994. Diario inédito (varios volúmenes manuscritos).

Antonia (pseudónimo). Inédito. Diario de Antonia (1978-1981).

Astudillo, Ester. Inédito. Diario de Ester (1980-1984).

Civera, Mariano, y Ramos, José. 1966. Diario de Juani. Bilbao: Mensajero.

Corrado, Danielle. 2004. "L'hôte intime: figures du narrataire dans le journal”. En: Montandon, 83-96. 
Debesse, Maurice. 1941. La crise d'originalité juvénile. París: PUF.

1964. La adolescencia. Barcelona: Vergara.

Frank, Anna. 1952. Diario (Trad. de José Blaya Lozano). Prol. Daniel Rops. Buenos Aires: Hemisferio.

1955. Las habitaciones de atrás (Trad. María Isabel Iglesias). Barcelona: Garbo.

1993. Diario (Trad. Diego Puls). Barcelona: Plaza \& Janés.

García, Rosa. Inédito. Diario de Rosa (1987-1991).

Gúrpide, Carmen, Nuria Falcó y Ana Bernard. 2000. El diario personal. Propuestas para su escritura. Pamplona: Pamiela.

Lejeune, Philippe. 1989. Cher cahier... Témoignages sur le journal personnel. París: Gallimard. 1990. La pratique du journal personnel. CST, 17. París : Université París X.

1993. Le moi des demoiselles. París: Seuil.

2004. "Lucullus dîne chez Lucullus". En: Montandon, 97-105.

Lejeune, Philippe y Catherine Bogaert. 2003. Un journal à soi. Histoire d'une pratique. París: Textuel.

2006. Le journal intime. Histoire et anthologie. París: Textuel.

López Manchado, María del Carmen. 1954. Así era María del Carmen. Su diario espiritual. Burgos: Monte Carmelo.

Matute (pseudónimo). Inédito. Diario de Matute (1969-1972).

Montandon, Alain. 2004. Du soi à soi. L'écriture comme autohospitalité. Clermont Ferrand: Presse Universitaires Blaise Pascal.

Perrot, Michele, y Alain Corbain. 1989. Historia de la vida privada. De la Revolución francesa a la Primera Guerra mundial . Vol. 4. (Dir. Philippe Ariès y Georges Duby). Madrid: Taurus.

Quoist, Michel. 1964 y 1965. Dar. Diario de Ana María y Amar. Diario de Daniel. Barcelona: Herder. 